\title{
Detecção de potenciais marcadores moleculares séricos da doença de Hodgkin
}

\author{
Detection of potential serum molecular markers for Hodgkin's disease
}

Paulo Costa Carvalho'; Juliana de Saldanha da Gama Fischer2; Marcelo Soares da Mota e Silva ${ }^{3}$; Juliane Musacchio ${ }^{4}$; Nelson Spector ${ }^{5}$; Wim Maurits Degrave ${ }^{6}$; Maria da Gloria da Costa Carvalho

\begin{abstract}
unitermos
Linfoma

Doença de Hodgkin

Câncer

Proteinas de soro

Marcadores moleculares

resumo

Motivação: Neste trabalho foi analisado o perfil de proteínas séricas de pacientes com doença de Hodgkin (DH) localizada e avançada em busca de novos e potenciais biomarcadores para o diagnóstico médico. Materiais e métodos: O perfil de proteínas presentes no soro de 14 indivíduos saudáveis, 14 pacientes com DH avançada e 15 pacientes com DH localizada, assim como pools de soro dos respectivos grupos, foi analisado em gel desnaturante de poliacrilamida a $12 \%$ corado pela prata. A densitometria e a intensidade média das bandas de interesse foram estudadas utilizando-se o Kodak 1D Scientific Imaging System. Resultados e conclusões: O perfil protéico apresentou acentuada variação entre os pacientes examinados; entretanto foi observada a indução predominante de determinadas proteínas (aproximadamente $26 \mathrm{kDa}$ e $18 \mathrm{kDa}$ ), cuja expressão foi substancialmente diferente quando em comparação com os controles $(p<0,01)$. Estas proteínas podem potencialmente constituir-se em marcadores moleculares de acompanhamento da evolução e do tratamento da doença.
\end{abstract}

Aim: In this work the serum protein profile of patients with localized and advanced Hodgkin's disease (HD) was analyzed to search for new potential biomarkers of medical interest. Materials and Methods: The serum protein profile of 14 healthy donors, 14 patients with advanced disease, 15 patients with localized disease and serum pools of the respective groups, were analyzed using silver stained $12 \%$ denaturating polyacrylamide gel. The densitometry and mean band intensity from the bands of interest were analyzed using the Kodak 1D Scientific Imaging System. Results and Conclusion: The patients' protein profiles presented heterogenous variations; however over-expressed proteins of approximately $26 \mathrm{kDa}$ and $18 \mathrm{kDa}$ were proven to be statistically different when compared to healthy donors. Such proteins could potentially constitute in molecular markers for diagnosis

\section{key words} Lymphome Hodgkin's disease Cancer Serum proteins Molecular markers and patient treatment follow-up.

\footnotetext{
1. Mestrando em Biologia Celular e Molecular pelo Laboratório de Cenômica Funcional e Bioinformática do Instituto Oswaldo Cruz.

2. Mestranda em Clínica Médica do setor de Ciências Pneumológicas da Faculdade de Medicina da Universidade Federal do Rio de Janeiro (UFRI).

3. Aluno de iniciação científica do Laboratório de Controle da Expressão Cênica do Instituto de Biofísica Carlos Chagas Filho da UFR).

4. Doutoranda em Clínica Médica da Faculdade de Medicina da UFR.

5. Médico; doutor; professor-adjunto do Departamento de Clínica Médica do Hospital Universitário Clementino Fraga Filho (HUCFF) da UFRJ.

6. Doutor; e chefe do Laboratório de Genômica Funcional e Bioinformática do Instituto Oswaldo Cruz.

7. Médica; doutora; professora-adjunta; chefe do Laboratório de Controle da Expressão Cênica do Instituto de Biofísica Carlos Chagas Filho da UFRJ; chefe de pesquisa básica do Laboratório de

Oncologia Molecular do Serviço de Pneumologia do HUCFF/UFR).
} 


\section{Introdução}

A procura por marcadores moleculares para o diagnóstico de tumores é uma área de intensa atividade na pesquisa médica atual. A busca por marcadores séricos fundamenta-se no conceito de que algumas substâncias específicas são liberadas pelas células tumorais ou pelo organismo hospedeiro em resposta à presença do tumor ${ }^{(1)}$. Um marcador tumoral pode ser definido como qualquer substância da célula tumoral que esteja correlacionada com apresentação clínica do tumor, seu crescimento ou mudança de tamanho após o tratamento. Um marcador ideal deve ser específico do tumor, capaz de distinguir as células tumorais em estágio precoce e ter seu nível de expressão correlacionado com a massa tumoral, e seu método de detecção deve ser sensível, de fácil realização e baixo custo. Um único marcador com todas essas características é muito difícil de ser encontrado. Assim, a investigação de um amplo painel de possíveis marcadores poderá permitir uma maior certeza no diagnóstico e a sua efetiva utilização na prática clínica(2).

O objetivo deste trabalho foi analisar o padrão de proteínas séricas de pacientes com doença de Hodgkin ${ }^{(3-5)}$, um linfoma caracterizado pela presença da célula de ReedSternberg (RS), em estágio localizado ou avançado, em busca de novos potenciais marcadores.

\section{Material e métodos}

\section{Pacientes e amostras de sangue}

Amostras de $5 \mathrm{ml}$ de sangue foram coletadas em tubos sem anticoagulante de 14 voluntários saudáveis (controles), 15 pacientes com DH localizada e 14 com DH avançada. $\mathrm{O}$ soro foi extraído através de centrifugação a 1.400xg por 15 minutos e armazenado a $-80^{\circ} \mathrm{C}$ até o seu processamento.

Os dados demográficos e histopatológicos (sexo, idade, tipo histológico do tumor, estadiamento) dos pacientes foram registrados. $\mathrm{O}$ soro dos pacientes foi coletado antes do início do tratamento. O estudo foi aprovado pelo comitê de ética da Universidade Federal do Rio de Janeiro (UFRJ).

\section{Eletroforese em gel de poliacrilamida (SDS-PAGE)}

Foram feitos três pools de soro: um contendo oito amostras dos controles, outro com oito amostras de $\mathrm{DH}$

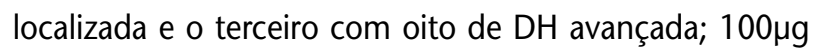

de proteína de cada amostra foram diluídos em $20 \mu \mathrm{l}$ de tampão de amostra (glicerol a 10\%, SDS a $2 \%$, DTT a $100 \mathrm{mM}$, azul de bromofenol a $0,02 \%$ ), aquecidos a $100^{\circ} \mathrm{C}$ durante 5 minutos e fracionados por eletroforese em gel de poliacrilamida a $12 \%$ segundo a técnica descrita por Laemmli em 1970(6).

\section{Coloração do gel de proteínas pela prata}

Após a corrida eletroforética, o gel foi submetido a impregnação pela prata. Para isso foi fixado por 30 minutos em solução contendo $50 \%$ de metanol e $10 \%$ de ácido acético. Após a fixação, procedeu-se à incubação por 30 minutos em solução descorante (ácido acético a 7\% e metanol a 5\%) seguida de 5 minutos em glutaraldeído a $10 \%$. Após esta etapa, o gel foi lavado abundantemente em água deionizada por 2 horas, incubado por 30 minutos em solução de DTT $(5 \mu \mathrm{g} / \mathrm{ml})$ e, em seguida, incubado com solução de nitrato de prata a $0,1 \%$ por 30 minutos. Para a revelação, o gel foi lavado rapidamente em água deionizada e colocado em solução contendo formaldeído a $0,0185 \%$ e carbonato de sódio a 3\%, até o aparecimento das proteínas. A reação foi inativada pela adição de $115 \mathrm{mM}$ de citrato de sódio(7).

\section{Quantificação das bandas de interesse e análise estatística}

Após a inspeção visual dos géis, foram observadas duas bandas superexpressas em pacientes com $\mathrm{DH}$ de peso molecular aproximado de $26 \mathrm{kDa}$ e $18 \mathrm{kDa}$. Os géis foram escaneados e a densitometria e a quantificação da intensidade média das bandas de interesse foram analisadas utilizando-se o Kodak 1D Scientific Imaging System v.3.5.3. O teste $t$ de Student não-pareado foi aplicado para verificar se os grupos DH localizada e DH avançada eram estatisticamente diferentes com base na intensidade média das bandas de interesse.

\section{Resultados}

A análise visual do gel evidenciou que a região com a maior diversidade entre os pacientes e os indivíduos saudáveis foi a de baixo peso molecular. A Figura 1 mostra a região de interesse do gel $(15-30 \mathrm{kDa})$ proveniente dos indivíduos saudáveis, dos pacientes com DH localizada, DH avançada e dos respectivos pools.

Embora o perfil protéico apresente variações entre os pacientes com $\mathrm{DH}$ avançada ou localizada, os resultados 
mostram, em ambos os casos, uma clara indução das proteínas de 26 e $18 \mathrm{kDa}$. Para melhor discriminar entre a intensidade das bandas dos grupos, foi feito um boxplot (Figura 2) usando-se o programa Minitab v14 (Minitab Inc. ${ }^{\circledR}$ 1972-2003).

Por convenção, um marcador foi considerado expresso quando a intensidade média de sua banda superava pelo menos duas vezes a intensidade média do background do gel $(2 \times 25)$. Nos pacientes com HD localizada, ambas as proteínas, de 26 e $18 \mathrm{kDa}$, mostraram-se induzidas em 13/15 pacientes (87\%) (26kDa nos pacientes: 4, 6, 7, 11, 17, 19, 24, 30, 32, 38, 45, 50, 53 e 18kDa nos pacientes 4, 6, 7, 11, $17,19,24,30,32,38,45,50,53)$. Nos pacientes com DH avançada, a proteína de 26kDa estava induzida em 12/14 pacientes (86\%) (pacientes 3, 13, 14, 18, 21, 22, 23, 28, $5,12,15,16)$, e a de $18 \mathrm{kDa}$, em $10 / 14$ pacientes $(71 \%)$ (pacientes $3,8,10,18,21,28,5,12,132,16)$. As proteínas de 26 e $18 \mathrm{kDa}$ também foram induzidas nos controles 300 e $302(2 / 14,14 \%)$.

$\mathrm{O}$ teste $t$ de Student não-pareado mostrou que os grupos DH localizada e avançada são diferentes quando comparados ao grupo controle com base na intensidade média das bandas de 26 e $18 \mathrm{kDa}$, respectivamente $(p<$ $0,01)$. Quando comparada a intensidade média da banda de 26kDa entre os grupos de DH localizada e avançada, foi obtido um valor de $p$ de 0,23 . Apesar de não ser considerado estatisticamente diferente, este valor sugere uma tendência de maior expressão desta banda protéica na fase inicial da doença.

\section{Conclusões}

O grande interesse no estudo do proteoma do soro reside no fato de que o mesmo pode ser obtido facilmente, e espelha uma amostra do estado geral do organismo em determinado momento(1).

Estudos recentes vêm mostrando que, independente da identidade das proteínas, o padrão proteômico do soro pode ser um fator discriminatório entre os estados normal e patológico. No presente trabalho, foi analisado esse novo paradigma de avaliação molecular de uma doença neoplásica. Foram evidenciadas alterações no padrão protéico do soro de pacientes com doença de Hodgkin que podem ser detectadas por uma metodologia simples e de baixo custo, aplicada em material biológico de fácil obtenção. Embora o padrão de proteínas séricas dos pacientes examinados apresente variações individuais, observam-se variações relevantes quando os pacientes são comparados aos controles

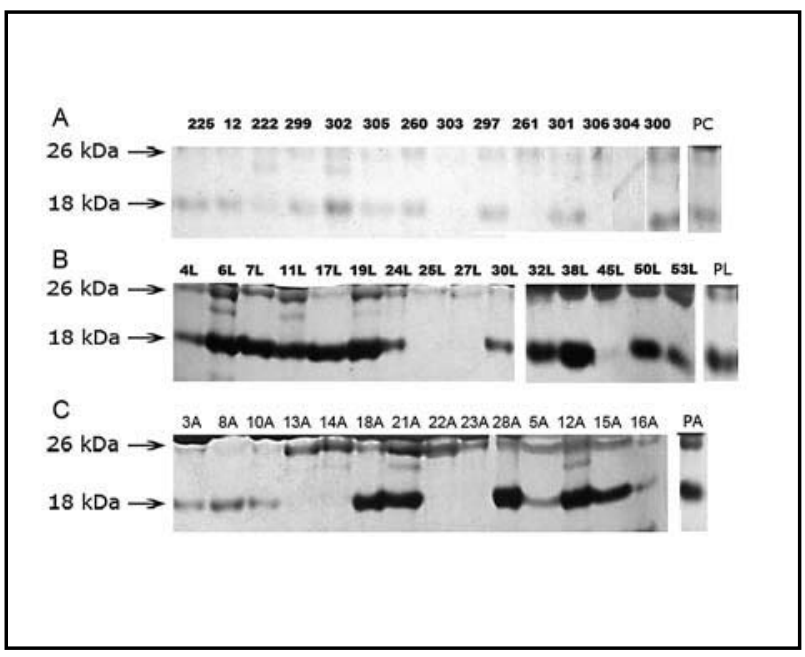

Figura 1 - Eletroforese de proteínas do soro em gel de poliacrilamida a 12\% corado pela prata. A figura mostra a região compreendida entre 15 e 30kDa. 1A: indivíduos teoricamente saudáveis; $1 \mathrm{~B}$ : pacientes com DH localizada; 1C: pacientes com DH avançada. PC: pool controle; PL: pool DH localizada; PA: pool DH avançada. Os números acima dos canais identificam os indivíduos e são seguidos de L (localizada) ou $A$ (avançada)

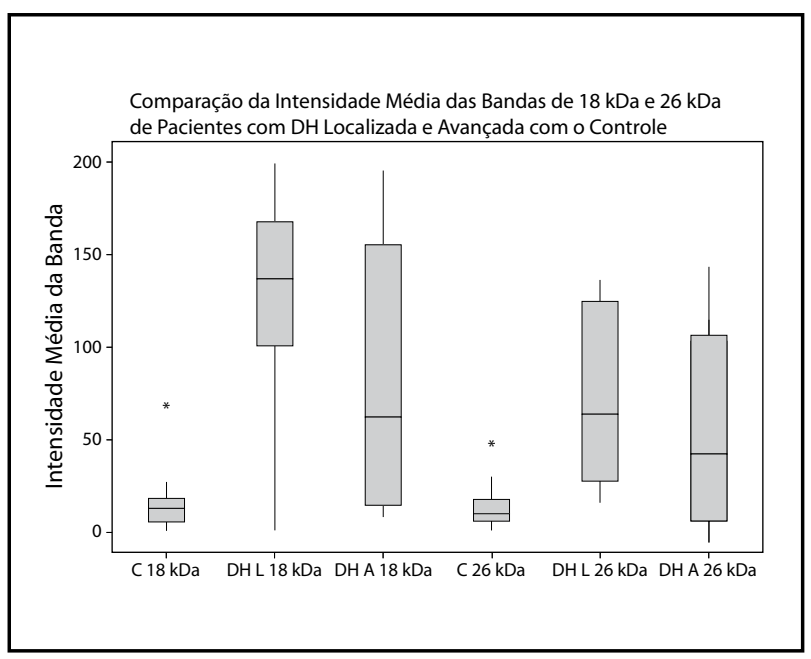

Figura 2 - Boxplot da intensidade média da banda versus controle $18 \mathrm{kDa}$ (C $18 \mathrm{kDa}), \mathrm{DH}$ localizada 18kDa (DH L 18kDa), DH avançada (18kDa), controle 26kDa (C 26kDa), DH localizada 26kDa (DH L 26kDa) e DH avançada (DH A $26 \mathrm{kDa}$ ). A intensidade do background do gel de valor 25 foi subtraída dos valores

saudáveis. Estas proteínas poderão, potencialmente, ser utilizadas como marcadores moleculares de acompanhamento da evolução e tratamento da doença.

\section{Agradecimentos}

Fundação Charles Darwin, Conselho Nacional de Desenvolvimento Científico e Tecnológico (CNPq), Fundação Oswaldo Cruz, Programa de Apoio à Pesquisa Estratégica em Saúde, Programa de Desenvolvimento Tecnológico em Insumos para Saúde, Instituto Oswaldo Cruz (FIOCRUZ/PAPES/PDTIS, IOC). 


\section{Referências}

1. Anderson, N. L.; Anderson, N. G. The human plasma proteome. Mol Cell Proteomics, v. I, p. 845-67, 2002.

2. Fleischhacker et al. Molecular genetic characteristics of lung cancer: useful as "real" tumor markers? Lung Cancer, v. 25, p. 7-24, 1999.

3. GLASER, S. L.;JARRET, R. F.The epidemiology of Hodgkin's disease. Bailliere's Clin haematol, 9: 401-16, 1996.

4. MULLER, N. E. et al. Cancer Epidemiology and Prevention. New
York: Oxford University Press, 1996. p. 502-31.

5. KAPLAN, H. S. Hodgkin's disease. Cambridge, MA: Harvard University Press, 1980.

6. LAMMLI, U. K. Cleavage of structural proteins during the assembly of the head of bacteriophage T4. Nature, 227: 680-5, 1970.

7. AUSUBEL, F. M. et al. Short Protocols in Molecular Biology. 5. ed. New York: John Wiley \& Sons, Inc., 1999. p. 10.37-8. 